\title{
Active Learning Methods in Nursing Education - A New Paradigm?
}

\author{
By Maj-Helen Nyback
Irén Vikström
}

The overall aim of the ongoing research project is to develop new learning environments in nursing education, adapted to latest technology and active learning methods. The present research focuses on the students' satisfaction with the active learning methods used in the course "Basic Nursing Skills" in which theoretical and practical elements are included. Blended learning environments have been used, which are represented by traditional classroom teaching, self-directed studies, written assignments and the flipped classroom. The research has a qualitative research design and the sample used is the first-year students in the English Degree Programme in Nursing at Novia University of Applied Sciences. Finland is a bilingual country with Finnish as the language for the majority and Swedish is the minority language. Novia UAS is a University with Swedish as main language and the English Degree Programmes at Novia UAS are few and small. The study applies constructivism as the underpinning philosophy of active learning, and coaching as the approach to teaching. Contact teaching consists mainly of an introduction, supervision, and evaluation. The students receive carefully designed guides for expected learning outcomes. Regarding the practical parts, the students have access to instruction films and a laboratory environment for practice. The students decide when they are ready for their given practical procedure to be evaluated, and record the procedure with their own devices. The students' videos are uploaded as unlisted on YouTube and sent to the teacher, who subsequently evaluates the students' performances of the given procedure. The study also investigates student views on the flipped classroom-technique where the classroom is transferred to a bed ward with several, mainly elderly, bedridden patients at a local health care center. The overall student response is positive, the students felt that the methods used provided a good way of attaining deep insights into the subject and that the variety of methods and tasks stimulated learning.

Keywords: Active learning, Basic Nursing Skills, Blended learning, Nursing education, Virtual learning environment.

\section{Introduction}

Due to the rapid development of nursing care methods and diverse health problems, the contemporary nurse needs creative thinking to handle complicated health issues, as well as skills for developing appropriate solutions to diverse problems. Creative thinking has been described as the ability to design fluent, flexible, and unique nursing interventions which could apply to nursing care easily and conveniently (Ku 2015). It is important to develop learning environments that enhance creative thinking and support self-directed learning. These skills not only support the nurses in handling the current challenges, but also help them in meeting future challenges.

Over the past years, nursing education has implemented a variety of technological formats to enhance the teaching-learning environment. Latest technology has transformed the access to information and education. Virtual

\footnotetext{
${ }^{*}$ Principal Lecturer, Novia University of Applied Sciences, Finland.

${ }^{\dagger}$ Senior Lecturer, Novia University of Applied Sciences, Finland.
} 
learning environments (VLEs) are commonly used worldwide as teaching and learning platforms (Wilson and Hungerford 2015, Allen 2013, Condon 2013); and Moodle is one of the platforms used for the virtual room (De Domenico and Cohrs 2016, Seixas et al. 2012). A virtual room or VLE can also be a MOOC (Massively Open Online Course) in a university sphere (Skiba 2013, Allen 2013), or a virtual room where social media is used as the meeting place for students from diverse cultures and parts of the world (Chan and Nyback 2015, Nyback 2016).

In 2013, Novia University of Applied Science (Novia UAS) launched a project named "Development of new learning environments at Novia UAS, DP in Nursing". The initial project was funded by the European Social Fund and lasted for 2 years. It was the starting point for a journey with, as of yet, an unknown destination. The need for a change in teaching methods was obvious, and a creative approach to the development of teaching and learning methods was applied. The development of learning environments is still in progress; and even though the initial project span has ended, new projects have been developed based upon the first one. We are merging the concept of learning environment with VLEs and VCP (Virtual Clinical Practice), developing Global Classrooms, and investigating possibilities for home-internationalization. Furthermore, we explore blended learning environments (Graham and Dziuban 2013), which includes flipped classroom, traditional lectures, case studies, self-group and individual work and evaluation.

Phase one, carried out during the initial project, was a pilot study aiming at exploring the possibilities for how social media can support homeinternationalization (Chan and Nyback 2015). In this study, the virtual room was used as a meeting point, and social media were used as facilitators to communicate and collaborate. The results showed that students, by using social media, learn from each other and develop an understanding for diverse cultural traditions, meanings and values through, for example, developing cultural competence. Using social media for communication is an essential skill in a digital age (Bates 2015).

Phase two is ongoing, and focuses on the use of blended learning environments in subjects related to interventions and caring activities. A variety of methods are used, such as contact teaching, case-studies, clinical training, working in teams and self-directed learning.

\section{Aim and Research Design}

The overall aim of the ongoing project is to develop new learning environments in nursing education adapted for latest technology and active learning methods. The present study focuses on students' satisfaction regarding active learning methods used in the course "Basic Nursing Skills". Blended learning environments such as traditional classroom teaching, self-directed studies, written assignments, and the flipped classroom have been used. This study has a qualitative research design with a small sample and new research innovations are in process. The research questions are as follows: 
1. How do students perceive their learning experience when using active learning methods?

2. How do students perceive the flipped classroom - when the classroom is moved out of school to a bed ward at a health care center?

The research applies constructivism as the underpinning philosophy of active learning, and coaching as the approach to teaching. The research is approved by the board for ethical review at Novia University of Applied Sciences. The studies are visualized in Figure 1 which is constructed by the authors of the article.

Figure 1. Developing New Learning Environments at DP in Nursing, Novia UAS

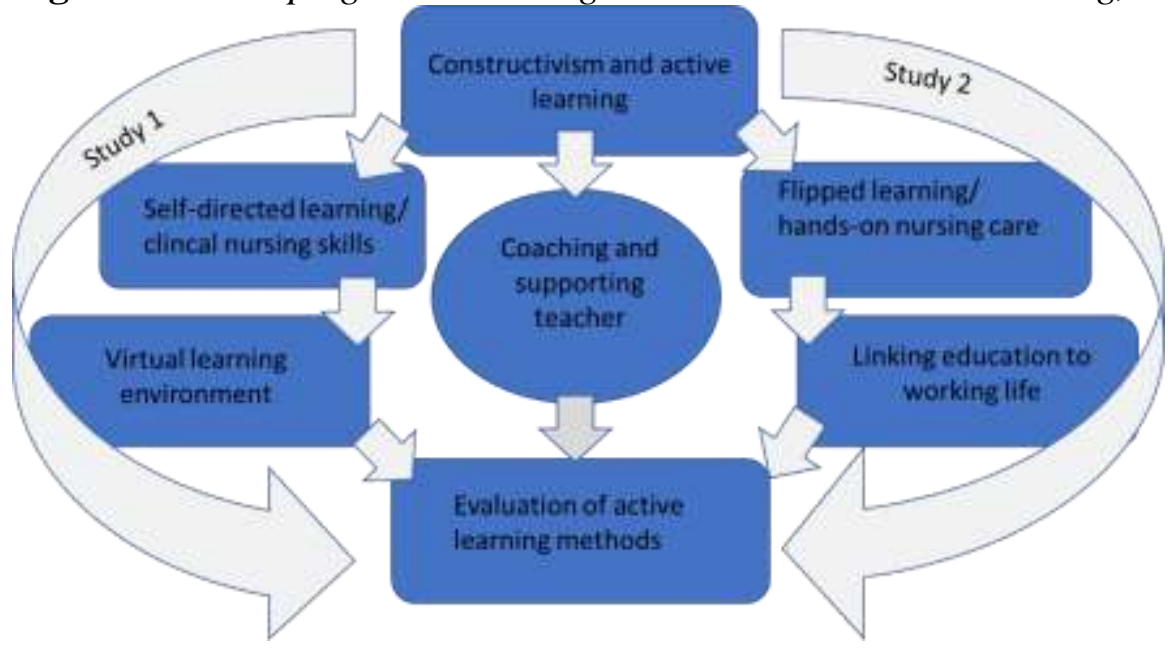

Figure 1 shows constructivism and active learning as the starting points for developing new learning environments and coaching as the main method to complete constructivism in action. The created learning environments move from the traditional classroom to a virtual platform in study 1 , and to the flipped classroom in a real nursing environment, in study 2 . The project was carried out in 2014, and the evaluation of the outcome took place in 2015.

\section{Constructivism as the Underpinning Philosophy for Active Learning}

A constructivist approach focuses on the learner and his/her experiences, and how new knowledge can be built on these (Powell and Kalina 2009), as well as on individual development through reflection on past experiences (Kolb 1984). Constructivism emphasizes the importance of the student being actively involved in the learning process (Nyback 2013). Merriam et al. (2007) and Torre et al. (2006) outline knowledge as being transferred when individuals attach meaning to an experience or activity.

The basis for personal constructivism can be traced back to Piaget, whereas Vygotsky has developed many of the ideas related to social constructivism (Nyback 2013). Rutherford-Hemming (2012), based on Piaget and Vygotsky, distinguishes between personal and social constructivism. In personal 
constructivism, learning is constructed within the individual and based on prior knowledge; whereas, social constructivism posits that learning is constructed in a social environment. With personal constructivism, the learner attaches meaning using previous knowledge and experience; an internal change in cognitive schemata occurs because of the learner's connection to the current environment. Social constructivism results from individuals dialoguing about problems in a social environment (Nyback 2013).

Splitter (2009) describes constructivism as an epistemological and psychological theory about how we learn by actively and consciously bringing our past experiences and understandings into a collaborative exercise with others as we process, interpret, and negotiate the meaning of new information. We all generate our own "rules" and "mental models" which we use to make sense of our experiences.

\section{Active Learning}

Active learning is a student-centered teaching strategy that helps students become actively engaged in their learning opportunities (Shin et al. 2015). Students become actively engaged in the topic when instructors create opportunities for their participation (Stevenson and Gordon 2014); and students learn when curricular goals and content are transformed into experiences (Oliva 2009). A problem- and/or project based approach to teaching methods can use constructivism as the basic philosophy and active learning methods as concrete tools to support the students' creation of meaningful experiences. When coaching the students towards self-directed learning, the teacher provides them with skills for "life-long-learning" (Nyback 2013).

Shin et al. (2015) found that active learning strategies had a positive effect on nursing students' core competency, in terms of the balanced achievement among all subdomains of nursing core competency and better clinical competency. Competency, particularly the clinical competency of new graduates, has been identified as an area of nursing education that suffers from a statistically significant deficiency; and there have been issues with understanding and implementing the nursing process (Beischel and Davis 2014). These findings clearly suggest the need to find more innovative and effective ways of teaching and learning (Shin et al. 2015).

\section{Motivation for Learning}

Motivation is a key concept in learning, and it is dependent on the student's confidence in his or her potential. The sense of competence and belief in the potential to solve new problems derive from first-hand experience of mastery of problems in the past, and such experiences are more powerful than any external acknowledgment. According to the constructivist approach, the teacher needs to adapt to the role of mere facilitator rather than a teacher, even though both roles 
and ways of teaching/facilitating must be outlined according to the need of instruction (guidance) and subject (Nyback 2013).

The facilitator supports the student in attaining his/her own understanding of the content and allows the student to actively participate in the learning process. A facilitator is in continuous dialogue with the student. While students should be given ownership of the problem and solution process, the teacher must not condone all activities and solutions. The critical goal is to support the students in becoming effective thinkers. This can be achieved by assuming multiple roles, such as consultant and coach (Chin 2008, Splitter 2009, Sylvest 2010).

\section{Coaching and Self-Directed Learning}

For decades, the main teaching method in higher education has been the knowledge tranfer-model. Nursing education encourages reflective thinking, nursing skills, and the ability to make decisions and act. Therefore, a different teaching and learning style is required. The role of the teacher must change from "speaker" to "facilitator" and "supporter". Coaching is today a recognized discipline used by many professionals engaged in human development. However, as a distinct profession, it is relatively new and self-regulating. Coaching has emerged as a cornerstone of learning organizations in which personnel development is a high priority (Nyback 2013). Coaching is commonly used when discussing clinical training and practice-based teaching in nursing education (Huggins 2016); but it is also necessary to shift the pardigm of teaching to a coaching approach in theoretical studies to enhance creative thinking and active learning.

Coaching is rooted in the field of behavioral psychology and its domain is in organizational development, education, and personal growth. Coaching consists of the teacher asking thought provoking questions, listening actively and reflecting authentically to share valuable observations without generating defensiveness. This explains why coaching can be adapted as a method for supporting the students in finding their own constructs of knowledge which are linked to facts, reality, and place (Nyback 2013).

Coaching can be visualized as a pyramid, where the process of learning is the base, diferent milestones as the next level, the goal as the third, and the fulfilled dream on the top. Based on Nyback (2013), the dream is the trigger (the reason for why a nursing student applies for a place in a Degree Programme in Nursing) and the process begin when the student constructs his/her own meaning ("how can I use what I learn"). The student is then, with the help of the coach, able to outline the path that will lead to a degree, (criteria required to become a nurse) and, if possible, fulfill the dream (which might change during the process, due to new insight). In Figure 2 the coaching process is described. The picture is inspired by Nyback (2013). 
Figure 2. The Coaching Process

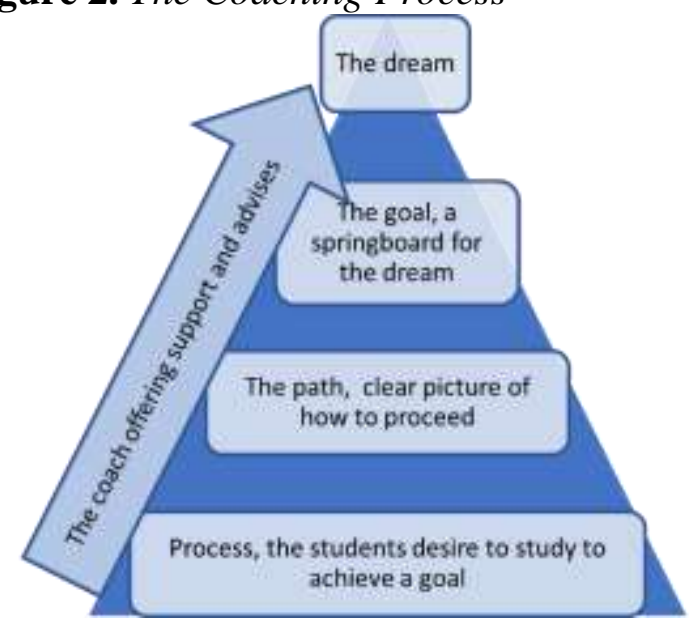

Based on Phillips (2006), coaching is a way of developing skills and selfconfidence among nursing students and can, according to Chin (2008), help the students structure their studies and find a way out of a troublesome situation.

Coaching, based on a constructivist paradigm, can encourage the student to participate in self-directed studies: the student has the possibility to influence the process which is steered by the student's own will to develop, and the new insights carry a meaning for the student. Studies are not an instrument to get a degree - studies are the instrument for fulfilling the dream; and the degree is just a part of the dream.

\section{Diverse Learning Environment}

Education today is changing, and it raises the demand for a more flexible learning environment. Studies that are offered throughout the year and that are independent of time and place are in high demand. A learning environment refers to physical locations, contexts, and cultures in which students learn (Bates 2015), and a virtual learning environment refers to a location not tied by geographical bounds or dependent on time (Hilli 2016, Revaitis and Egger 2013). Virtualization is a key education policy goal in Finland (OPM 2011). A virtual environment has a positive impact on students' cognitive learning processes as students are increasingly expected to seek knowledge independently and critically assess the information they receive (McCutcheon et al. 2015). When advocating a life-long learning process, it is important that students can independently search and update their skills using virtual resources.

Working in a virtual learning environment requires social networks, technical insights, and good planning by the teacher, as well as an awareness of the students' different learning styles (Laru 2012, Suominen and Nirmala 2011). Virtual learning environments are not limited to platforms (e.g. Moodle, Blackboard) and applications. Interactive virtual learning environments are also important for enlarging the body of knowledge, e.g. the use of "Global Classroom" and other virtual social media. Blended learning environment (also 
known as hybrid learning and mixed-mode learning) is a combination of different methods integrating online activities with traditional face-to-face activities in a planned, pedagogically valuable manner (Bonk and Graham 2012, Graham and Dziuban 2013).

The concept of flipped learning is also used in discussions about virtual learning environments. Flipped learning is a pedagogical approach (also known as inverted instruction, backward class, up-side-down teaching) where direct instruction moves from the group learning space to the individual learning space. The students are expected to apply and expand their knowledge by solving problems and by working on projects. The educator guides students as they apply concepts and engage creatively with the subject matter (Crews and Butterfield 2014). However, even though there is rapid development of learning environments in contemporary society, not all education can be virtual or flipped - traditional classroom teaching is also needed.

Clinical skills taught in a laboratory environment are important parts of nursing education. A laboratory environment consists of a classroom simulating a real nursing environment with beds, mannequins, and equipment needed for nursing care. A laboratory environment can also have automated mannequins (Sim-man). Simulation of real situations and the use of mannequins began in the 1980s (Moule 2011, Durham and Alden 2008, Ricketts et al. 2012) and provides an important learning environment to this day. The simulation learning events should be supported by a teacher who understands the components and can consolidate observations of student actions into a valid evaluation using objective structured clinical examinations (OSCE) (Rushforth 2007). Today we also have the possibility to simulate real situations in virtual simulation environments (Second Life) which can facilitate the students' ability to carry out nursing actions. This can be seen as a safe learning environment (Kidd et al. 2012). Virtual simulation environments can also be used for learning communication and a readiness to act (Hilli 2016). The virtual simulation environment is computer-based, and is therefore available outside the laboratory environment (the school), which allows for a flexible learning environment that is not tied to place and time.

\section{The Case - Basic Nursing Skills}

Basic Nursing Skills is a course $3+3$ credit units (cu) offered in the first year of studies. One credit unit is equivalent to 27 hours of studies, and the total number of working hours for the student is 162 hours. The course is one of several implemented during the first year with the number of scheduled hours varying 4 to 12 hours per week. The self-directed studies in the theoretical part are expected to constitute $50 \%$ of the time; and the clinical training has traditionally been scheduled up to $90 \%$ of teacher-led studies.

Traditionally, the course in Basic Nursing Skills consists of teacher-led lectures, demonstrations in a laboratory environment, supervised practice in a laboratory environment, and the evaluation of students' skills in a laboratory 
environment. This project entails a change in teaching methods adapting constructivism and blended teaching methods.

The change of teaching methods affects all stages of the course. Contact teaching is used when giving the instruction about the course (working methods, literature, evaluation methods), different topics within the course, demonstration of nursing procedures, as well as guidance about self-directed learning and group-work. Supervision is offered only when the students ask for it. The theoretical parts apply a case study-approach. For the clinical training in a laboratory environment, the students have access to instruction films and the opportunity to book the laboratory classroom for self-directed practice.

The expected outcomes are good clinical skills in basic nursing, an increased interest in self-directed studies, use of virtual learning environments, and experience with skills needed in nursing care of patients. Figure 3 displays a visual outline of how the course is carried through.

Figure 3. Flow Chart of the Course in Basic Nursing Skills (Nyback and Vikström)

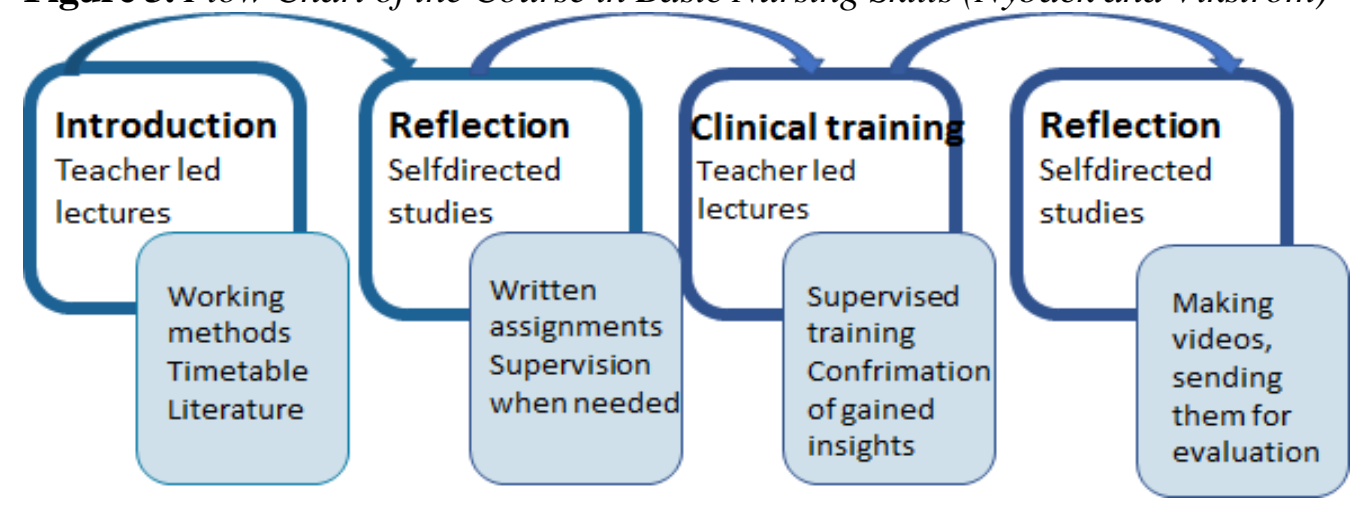

The figure outlines the blended learning method where the teacher gives information followed by the students' self-directed studies and reflections resulting in written assignments submitted to the teacher. The written assignments focus on different topics on the subject and are done as group-work. Supervision is provided if asked for.

A total of 75 instruction films were made during the project and were uploaded to a Moodle-page accessible for all students enrolled in the course. The instruction films cover all clinical training in the course. The students can open the films on their mobile phones, tablets or computers. When the students have submitted their written assignments and become acquainted with the instruction films, they can ask for a teacher-led demonstration of procedures if needed. The laboratory environments are available for the students for clinical training, but they need to book the equipment and room in advance. The student decides when the teacher evaluates the performance of the given procedure. When they are ready for the evaluation of the given practical procedure, they video record it with their own devices. The students' videos are uploaded as unlisted on YouTube and sent to the teacher. Each student uploads a total of 8 videos to be evaluated. 
Consequently, the students need to plan their self-directed studies, book time for their practice session, and plan how to get the videos recorded with their own device. Picture 1 is a print screen of a Moodle page showing two of the instruction films uploaded for students.

Picture 1. Instruction Films Uploaded to Moodle Platform Available for all Enrolled Students (Novia UAS, uploaded to Moodle by Vikström, 2014)

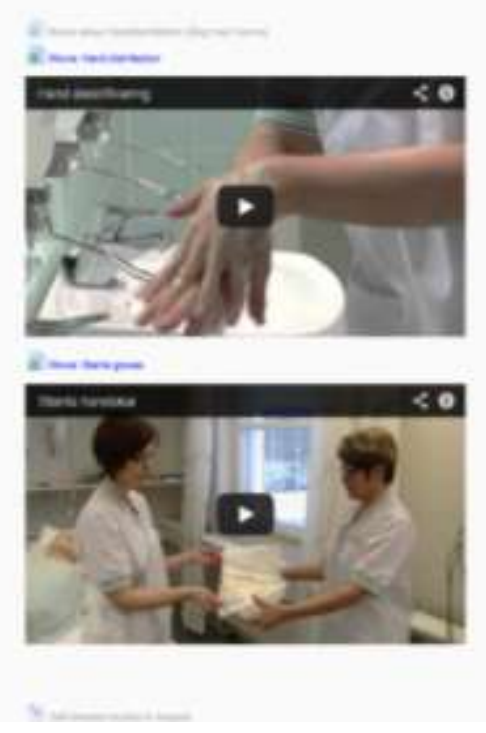

\section{Methodology}

The research is carried out according to a qualitative research design inspired by Maxwell (2013), which implies a small number of informants and several variables to consider. It is not aiming at generalization, but merely to depict the process of shifting the paradigm towards an active learning approach.

\section{Data Collection}

The data collected were student responses to open-ended semi-structured questions that were formulated based on the constructivist and active learning framework of the study. These were written in a questionnaire administered to the students. Consequently, the questions related to the students' satisfaction with the methods (self-directed studies, teamwork, and the use of videos for evaluation) used during the course and the experience of moving the laboratory environment to a real-life situation in a bed ward. The construction of the questionnaire is inspired by Trost (2007).

The sample consists of 15 first-year-students in the English Degree Programme in Nursing at Novia UAS and the answering rate is $93 \%$. The English DP in Nursing is a small programme (60 students in total, divided between students in first through fourth year of studies) with an international atmosphere. The language of communication is English; and the students in the 
entire programme currently represent 26 different nationalities. Following a discussion on ethics, the students completed the questionnaire during lecture time. The students were informed about anonymity, confidentiality, and the ability to withdraw at any time, without consequences. The students were all eager to answer the questions as this was an opportunity to influence the development of new learning environments.

\section{Data Analysis}

The data-analysis is conducted as qualitative content analysis following Elo and Kyngäs (2008). The focus is on the manifest message and the analysis has an inductive approach, which implies that all data material is one unit of analysis. The material is then digitally transcribed to a common file. The material is read through several times to achieve a deep understanding of the material. The next step is finding the manifest message of the unit of analysis. The material is coded and successively formed into sub-categories and categories.

\section{Findings}

The findings are presented in the form of two themes; Adopting an active learning approach and Transforming insights into practice. Each theme consists of categories illustrated by verbatim quotations from answers to questions in the open-ended questionnaires. The quotations enlightening the categories are not grammatically corrected. The categories for the theme Adopting an active learning approach are "Acquisition of knowledge", "Clinical training in a laboratory environment", and "Using new technology". The categories for the theme Transforming insights into practice are "Linking theory and practice", "Adaption to working life", and "Being at right place". Figure 4, displays a visual presentation of the results.

Figure 4. Findings (Nyback and Vikström)

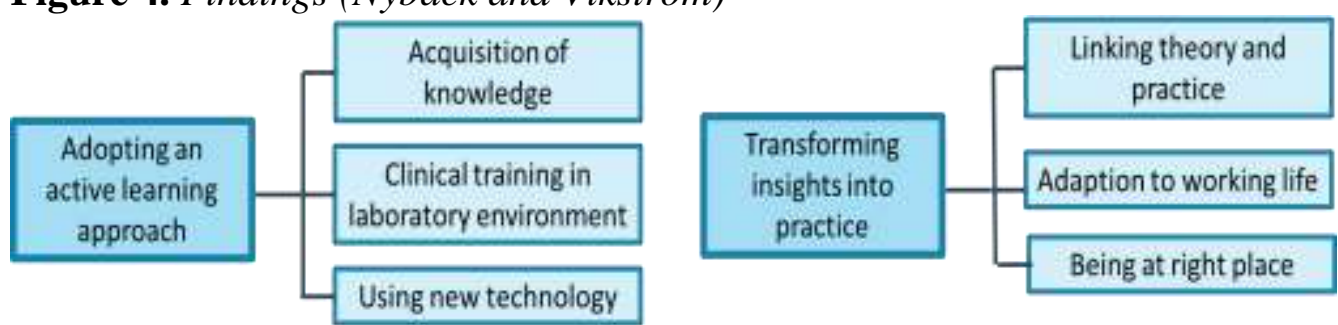

\section{Adopting an Active Learning Approach}

The theme describes how the students perceive the change in approach to teaching and learning when relating it to achieved knowledge. The changed approach requires a greater amount of self-directed studies, and the responsibility for learning clearly shifts from a traditional teacher-led teaching approach to a student-focused learning approach. This implies an independent working method 
where the student him-herself is responsible for the material used, to co-operate with other students in the group, and search for relevant literature (with guidance from a teacher, but only when asked for guidance). The teacher has the roles of facilitator, coach, and supervisor. The three categories are presented below.

\section{Acquisition of knowledge}

The students stated that the instructions given for the written assignments were good guidelines for achieving good basic nursing skills. The assignments supported them in getting an in-depth insight; they were encouraged to find several references for each topic and to go beyond using only the textbook for course materials. This also gave the students an understanding of the concept of evidence-based nursing care. The written assignment also connected to the students' previous experience and knowledge.

"It refreshes previous knowledge and at the same time it makes you read more detailed and understand the concept even better."

"The written assignment helps you to read through different source while you answering the question. In so doing to give a deeper insight of what we are writing on."

The students compared traditional teaching methods and active learning methods. They found that active learning methods required more self-directed study, but they also gained better insights. The students felt a higher level of independence in their study and could rely on their own capacity for studying. The teacher had a coaching approach when supporting the student.

"... we did a lot of work on our own so a lot of things got in the head and what you learn depends not much on the teacher."

"By working individually, not with PowerPoint done by teacher, I learned much more and at least $80 \%$ of it stayed in my head from the very beginning."

The written assignments were carried out as group work. The students experienced it as a useful way when learning from each other through discussions. They could relate to different references and benefited from the group's joint collection of knowledge. The teacher's approach as coach concerning literature was appreciated.

"They [the teacher] encouraged us to read more books, by being a group work we were able to discuss and practice our English writing skill as well."

"Self-directed studies enabled us enhance spirit by working in a group."

"The participation in our group was great, we were all working hard to get the assignments done properly and my group members were reliable and helpful."

The students were satisfied with the achieved outcome. They had learned more than expected, not only about the subject, but also about working together. 
Although they were forced to study more independently, they felt like they had gained much knowledge.

\section{Clinical training in laboratory environment}

The students, through self-directed studies assessed in the written assignment, developed an understanding of nursing skills. They expressed an understanding based on the underlying theory for how practices in basic nursing were conducted. The teacher gradually demonstrated the activities during the teacher led lectures and offered time for discussion and supervision during needed. After the demonstration, the students had the possibility to independently practice the activities demonstrated. The students had to organize the sessions in the laboratory, independently book the class, and agree on how and with whom they would practice the skills.

"Sometimes the practical sessions would get a bit chaotic with everyone scrambling around to find the equipment and start practicing."

"We had so big course that sometimes it was a bit messy around and took time to get teachers attention"

"[there was] enough time for practicing by ourselves to make sure that we know these skills. By doing the practical part by yourself one gets to remember the steps and procedure easily. Because you have to practice a lot before you do your final video."

The students had access to the laboratory environment, the equipment needed, and the supervising teacher when needed; but a few students were not ready for the independency and asked for more teacher-led practical activities. It took time to find the equipment needed for practicing the skills since the students were not familiar with how the laboratory was organized and they needed to, before the practice, book the equipment needed for the activities they should practice.

"The course can be improved to by doing more [teacher-led] practical activities."

"Maybe some more [teacher-led] practice with harder parts ... ."

The students also wanted more attention from the teacher to confirm and guide their skills; and they also asked for more practical activities.

\section{Using new technology}

The students had access to instruction films made by the teachers. The films were uploaded to Moodle and accessible through tablets and mobile phones. The students found the films valuable when practicing skills and were satisfied with the easy access. The students also confirmed the instructions given by checking with other available sources, such as YouTube.

$$
\text { "[the instruction films] ... were very educative." }
$$


"I checked out other movies in the YouTube to get more information ... ."

The students had to manifest their own skills through video recordings as well. The videos were also used for self-evaluation, as they had to record the video and look at it to find any mistakes before sending it to the teacher. The video was uploaded as unlisted on YouTube and saved with a personal code. The code was sent to the teacher, who would then watch it and evaluate it. The students experienced that recording the video of their practices was very educative and were also satisfied with the possibility of getting confirmation that their practices were correct.

"Doing the movies made us practice to master the whole procedure well." "The movies made us acquire new skills and through repetition the information sunk in."

"The movies allowed for a personal approach to our careers as healthcare professionals and gave us a lot of insight into how much responsibility and work goes into becoming a nurse."

The video recordings raised feelings ranging from positive to negative. The students described it as a way of learning not only clinical skills, but also acting and communication skills. It was also seen as positive to be able to learn from each other when recording the videos together, but it was perceived as difficult to make the videos when not used to acting.

"I [now] know the European way of doing these skills and I saw my mistakes on the videos."

"It's hard to make the movies, to find all the equipment, to talk in front of a camera (especially if you hate that, as I do)."

"By doing the practical part by yourself one gets to remember the steps and procedure easily. Because you have to practice a lot before you do your final video."

It was time-consuming to organize the video recording sessions; and the students needed help from each other in recording the video since there were no cameras in the laboratory class. A lack of time was also seen as a matter of organizing one's own schedule.

"Probably it is the amount of time I spent on it. But I can guess that it is more my problem with time-dividing."

"The movies took a lot of time to make since we had a lot going on in other courses too plus it was difficult sometimes to find someone to help record the video because of different schedules."

The use of technology for learning nursing skills got a mainly positive response. The instruction films were appreciated, as were the production of student videos. But not all students were positive - some negative responses concerning 
not feeling comfortable acting in front of a camera, asking classmates for help with recording, and finding time for doing the videos, were received.

\section{Transforming Insights into Practice}

This theme describes how the students transform the theory they have gained through the written assignments, as well as individual and group work, into practical skills. The theme describes the students' way of learning practical skills and how they adapt their skills in a real situation at a workplace. The three categories are presented below.

\section{Linking theory and practice}

The lectures and written assignment covered the theories of nursing skills (e.g. aseptic work, skin care and theories concerning health issues such as blood pressure, nutrition, etc.). The clinical training in a laboratory environment took place after the written assignment. The students felt satisfied with studying the theory in depth before practicing the procedures in a laboratory environment.

$" . .$. the lectures ... given in the beginning of the course ... gave us a great deal of knowledge before we started practicing"

"... classroom discussions, written assignment plus the practical videos we produce in the labs were of great importance."

The students had hands-on practice of the procedures learned in theory which strengthened their knowledge and gave a deeper insight. It also gave self-confidence; the procedures are not very complicated.

"It was really good, the practical part, when we got to practice the things we read about."

"The practical course was very helpful and the instructions were very clear and informative. The practical course allowed us to see hands-on that the theoretical knowledge we had wasn't that all complicated when we put it into practice."

Clear instructions supported the students in understanding the theory they had worked with in the group work. It also showed the students how practice, rather than exclusive theoretical study, is an effective approach to a practical skill.

\section{Adoption to working life}

After the clinical training was carried out in the laboratory environment and the students' skills had been approved, the laboratory environment was moved into a bed ward at a health care center. The students met patients in need of basic nursing care and could, in a safe environment with supervising teachers, practice the learned skills. Some of the students had never been in a bed ward before and they appreciated the experience and the encounters with both staff and patients. 
"It was my first experience in such place so it was very fruitful for me."

"The staff that showed us around too gave good information and supportive."

"It was a very good experience and a way to learn about bedridden patients."

They experienced new situations and new challenges in nursing care. The day also gave self-confidence and insight into their future work in nursing.

"We saw some cases (wounds) which I've never seen before and in the future, I would know what to expect."

"I was happy to be in a real life setting with the elderly and it was interesting to be in a room of elderly people suffering from different conditions. The activities that had to be done seemed relevant to me and I also learnt a lot ..."

The day at the bed ward in a real-life setting with situations that not can be completely re-created in a classroom or laboratory environment was fruitful for the students. They could practice skills learned in classroom and experience linkage between theory and practice.

\section{Being at the right place}

The day at the bed ward made it possible for the students to practice what they had learnt in school, not only in classes about basic nursing skills, but also in classes about ethics and encounters with patients. The day was stressful, but nevertheless informative and educative. The students expressed pride in their nursing skills and possibility to care for patients.

"Stressful, but it opened my eyes! It was so good because I was able to apply the knowledge that I learnt from school!"

"Was an informative and educative day."

The students expressed the difference between school practice and real-life practice. The experience the day in a real-life nursing setting gave cannot be created in a laboratory setting. The day confirmed to the students that the career they had chosen was the right one.

"It was interesting, useful and quite educational. Being in the real situations with patients, showed how ready I was for it and showed great difference between practice in school and personal experience."

"It was good, I was working with people who knows also what they were doing so it happened simultaneously."

The day also showed the need for teamwork in nursing care, and the students appreciated working with nurses who had long experience of working in nursing. The day confirmed the students' readiness for working in this field. 


\section{Discussion}

The overall aim of the project was to develop new learning environments in nursing education adapted for a change in approach to teaching and using active learning methods. The present research evaluates the implementation of new learning environments developed for enhancing active learning in a course with both theoretical and practical parts. The active learning methods were inspired by constructivism and by a coaching approach to teaching. The discussion is divided into two parts: the first one, a discussion about the result; and the second one discusses the limitations of the research.

\section{Discussion of the Results}

Constructivism as underpinning philosophy implies that new knowledge is based on previous experience, and that it is meaningful and specific to the learner (Powell and Kalina 2009, Kolb 1984, Merriam et al. 2007, Torre et. al. 2006). The results confirmed that the methods used received a positive response regarding acquisition of knowledge. The students were active in their learning process, which is one of the cornerstones in using constructivism (Nyback 2013). The positive response predominated in the study; however, negative experience was also reported. There were no participants reporting only negative experiences, but several reported only positive experiences.

The overall reported experience was that the active learning methods required more self-directed studies, but that they also gave deeper and more meaningful insights. This corresponds to findings by Shin et al. (2015). The students expressed that they incorporated new knowledge through self-directed studies. The problem-based approach in the written assignments and practice in the laboratory environment were of significant help to the students to see and understand the wholeness of the nursing procedures. This is in line with constructivism and an active learning approach (Nyback 2013). The approach is seen in the process of how the course is built. The first step consisted of reading the relevant theory and formulating a written assignment based on thoughtfully constructed guidelines for expected insights into the subject. The next step took the students to the virtual environment, here represented by the Moodle platform, to which instruction films were uploaded. This step enhanced the students own disposition of time, as the learning environment is not tied to time nor place. The third step was to transform the students' knowledge into nursing skills and record them on a video, which consolidated their newfound insights. The students had to actively participate, which created a sense of responsibility for their own learning, which is congruent with Stevenson and Gordon (2014) and Oliva (2009).

The arrangements and organization of activities were, nevertheless, reported as time- consuming. Active learning methods transfer the responsibility for learning from the teacher to the student, which also implies a responsibility for arrangements and for the use of time. The student had access to the laboratory environment, but a few students asked for more teacher-led practice time, and 
students also asked for feedback during the process, to be reassure that they carried out their tasks correctly. The students may not always be ready to take responsibility for their own learning; some might need more regular guidance to mature and be able to fulfill their dream.

It is important that the students are aware of the set expectations regarding the individual- and group work, the practical training in the laboratory environment, and the video recording. The students feel a responsibility for supporting each other which stimulates their development in working in teams. However, there were a few students who had difficulties with working in groups and with finding classmates to help them with video recordings.

Evidence of their factual knowledge was seen in the different evaluation methods. The theory learned was realized in the videos, and displayed their understanding of the topic and their ability to correctly use it in practice. The result is congruent with Oliva's (2009) observation that students learn when the content is transformed into experience, as it is in this case, when students record their videos. However, the recording of the videos generated varying experiences among the students. It was not a positive experience for all, as a few perceived it as stressful and unpleasant to watch themselves acting.

The teacher's coaching approach is of crucial importance to the students' learning. Coaching is used when discussing clinical training and practice-based teaching, but it is also necessary when supporting creative thinking and active learning. The results of these studies reflect the importance of a coaching approach, especially when applying the flipped classroom. The students noticed how the teacher and the nurses at the ward treated them, gave them space to practice and experience new situations. This is congruent with Shin et al. (2015) and Stevenson and Gordon (2014), who have outlined how students become engaged in learning when instructors create opportunities for their participation. The coaching approach encouraged them to practice their skills in, what was experienced as, a safe environment.

The students could also formulate that the flipped classroom helped them to see that the studies gave possibilities to fulfill their dream of a career in nursing. The studies were merely a tool for achieving their goal, not a goal per se. 


\section{Limitations of the Study}

The present research is part of a project aimed at developing new learning environments in nursing education. It focuses on active learning by using blended learning environments, here represented by virtual learning environments and flipped learning, along with fragments of traditional classroom-teaching.

The research has a qualitative approach with no intention to generalize the findings, nor to create a theory, due to its small sample. The research deals with several variables consisting of theoretical studies and its methods, as well as clinical training and its methods. The informants are students in an English Degree Programme in Nursing, which is an international programme consisting of students from diverse cultures with different nationalities, who form a heterogeneous group. This might influence the knowledge stemming from and experience of different learning methods. The results might be different if the research was done in a homogenous group with regards to age, nationality, and previous learning experiences. According to the constructivist approach (Powell and Kalina 2009, Kolb 1984 and Nyback 2013), the students bring their own experience into the situation where learning occurs and with the different learning experiences the students bring, the outcomes for everyone might differ. If the group is homogenous concerning the above-mentioned variables, the experience of new learning environments might be more similar.

The case is a course in the curriculum for first-year students in nursing education. The course includes both theoretical studies and clinical training in a laboratory environment. The course is 6 credit units which is equivalent to 162 working hours for the student. The change in teaching methods is massive, as the teacher-led studies are decreased in both the theoretical part and the clinical training part. The self-directed studies in the theoretical part are guided by instructions on a virtual learning platform (Moodle); and the clinical training has instruction films uploaded to Moodle. As the students participating in the research are first-year students and have no or little experience of how "traditional" teaching in nursing education is constructed, they, therefore, have no or little possibility to compare different learning methods. If the students had more experience in teaching and learning methods, their answers could have differed due to their ability to compare different learning experiences.

The research can due to the presented limitations only provide limited information and evaluation of the methods used. However, the results can be used as a springboard for more extensive research where several courses are included and the number of respondents is more representative of the average nursing student in Finland, rather than consisting of a small number of students in a heterogeneous group as this study represents.

The credibility of the research is discussed by using Patton's evaluation criteria (2001). Credibility requires a rigorous technique and method for data collection. The open-ended semi-structured questions used in the questionnaire were constructed based on the framework used, e.g. the constructivist and active learning approach. Consequently, the questions focused on the students' experience of obtained meaningful knowledge and practice. The data was 
collected after the course was held, to ensure the students had experience from all parts of the course and had the possibility to reflect on the wholeness of the methods used and gained insight.

Anonymity was guaranteed by the researcher. The informants could withdraw at any time without personal consequences. The students were also assured that their answers were anonymous and the confidentiality was kept prior to them writing the answers to the questions. However, the students are in a situation where they might feel the need to please the teacher with an overly positive response, since a dependency relationship exists between student and teacher. The student is dependent on the grades given which might affect the willingness of reporting negative experiences. This was discussed with the respondents before writing answers to the questions and they were assured that the response, positive or negative, was important for developing the active learning methods. The responses from the students were not only positive, but also negative responses were given which is seen in the reporting of findings. The responses were given after the students were given grades for the course.

A carefully conducted data-analysis is important for credibility of the study. The data was analyzed with peer debriefing to ensure objectivity. No data was excluded: all questionnaires were treated as one analysis unit. The findings are presented in themes with categories illustrated by quotations to ensure the reader of the correct interpretation of the result.

The research aims at being transparent. The underpinning philosophy is used in the interpretation; and the conclusions drawn can be related to the described theories and research within the field. Several quotations represent the categories and themes, which allow the reader to evaluate the conclusions and react if wrongful conclusions have been made or obvious relations have not been seen.

\section{Conclusion and Recommendation for Further Studies}

The main conclusion is that the students described their experience of active learning as a positive experience. They were satisfied with the learning methods and could also ascribe a personal meaning to the learned skills when practicing them in real life. This also formulates the answer for the first research question.

The flipped learning, when moving the clinical classroom to a real-life situation, was a positive experience concerning the consolidation of learned nursing skills. It was a positive experience to meet the patients and to experience that they could be a part of a theme in nursing care. The coaching approach to supervision was perceived encouraging the students to use their nursing skills. The students found the supervisors in the wards to be very patient with them which confirmed that they had chosen the right career. This formulates the answer for the second research question.

Based on the findings of this small project, it is clear that additional research with a larger cohort of participants would be beneficial to the 
furtherance of nursing science in the development of new student focused nursing education techniques. Since the number of first year students is limited in the English Degree Programme at Novia UAS, by program size, a study could be designed that examined student responses of successive year's cohorts and those groups compared with each other, or by incorporating the nursing students at Swedish Degree Programme in Nursing at Novia UAS which would enlarge the sample. Or, as indicated this is an on-going project, so, additional courses could be transformed to the new format and the same students could be followed as they progressed toward achieving their dream.

There is a need for evaluating active learning methods from the teacher's point of view as well. Active learning methods require efforts that are different from those in traditional teaching. The focus shifts from preparation of lectures with PowerPoint and a mediation of knowledge to a coaching approach where the students explore the knowledge themselves. This focus implies a thoughtful evaluation of the students gained insights to ensure that the references are correct and that the body of knowledge used is evidence-based.

\section{References}

Allen D (2013) Learning in a virtual world. Nursing Standard 28(16-18): 64-65.

Bates AW (2015) Teaching in a Digital Age. Retrieved from goo.gl/Jz1Cbx. [Accessed: February 01, 2017]

Beischel K, Davis D (2014) A time for change: QSENizing the curriculum. Nurse Educator 39(2): 65-71.

Bonk C, Graham C (2012) The handbook of blended learning. Global perspectives. Hoboken, New Jersey: John Wiley and Sons.

Chan A, Nyback M-H (2015) A virtual caravan-A metaphor for home-internationalization through social media: A qualitative content analysis. Nurse Education Today 35(6): $828-832$.

Chin H (2008) Making a fresh start. Nursing Management 15(2): 18-20.

Condon B (2013) The Present State of Presence in Technology. Nursing Science Quarterly 26(1): 24-28.

Crews T, Butterfield J (2014) Data for Flipped Classroom: Using Student Feedback to Identify the Best Components from Online and Face-to Face Classes. Higher Education Studies 4(3): 38-45.

De Domenico E, Cohrs C (2016) Moodle platform for the construction of knowledge in intensive care: an experimental study. Acta Paulista de Enfermagem 29(4): 381-389.

Durham C, Alden K (2008) Enhancing Patient Safety in Nursing Education Trough Patient Simulation. In R Hughes (Eds.), An Evidence-Based Handbook for Nurses. Rockville, MD.: Agency for Healthcare Research and Quality.

Elo S, Kyngäs H (2008) The qualitative content analysis process. Journal of Advanced Nursing 2(1): 107-115.

Graham C, Dziuban C (2013) Blended Learning Environments. In A Picciano, C Dziuban, C Graham (Eds.), Blended Learning, Research Perspectives. London: Routledge.

Hilli C (2016) Virtuellt lärande på distans. En intervjustudie med finländska gymnasiestuderande (Virtual learning at a distance. An interview study with Finnish 
high school students). University in Turku, Finland: Åbo Akademic Publisher. [In Swedish]

Huggins D (2016) Enhancing nursing students' education by coaching mentors. Nursing Management 23(1): 30-32.

Kidd L, Morgan K, Savery J (2012) Development of a Mental Health Nursing Simulation: Challenges and Solutions. Journal of Interactive Online Learning 11(2): 80-89.

Kolb D (1984) Experiential Learning: Experience as a Source of Learning and Development. Upper Saddle River, New Jersey: Prentice-Hall.

$\mathrm{Ku}$ Y-L (2015) Evaluating creative thinking of RN-BSN students in the course of clinical case study and practicum. Innovations in Education and Teaching International 52(3): 290-299.

Laru J (2012) Scaffolding learning activities with collaborative scripts and mobile devices - opiskelun tukeminen mobiilitaitteiden ja pedagogisen vaiheisuksen avulla. University of Oulu. Retrieved from goo.gl/AvTU8U. [Accessed: February 01, 2017]

Maxwell J (2013) Qualitative Research Design: An Interactive Approach. London: Sage Publications.

McCutcheon K, Lohan M, Traynor M, Martin D (2015) A systematic review evaluating the impact of online or blended learning vs. face-to-face learning of clinical skills in undergraduate nurse education. Journal of Advanced Nursing 71(2): 255-270.

Merriam S, Caffarella RS, Baumgartner L (2007) Learning in adulthood. San Francisco, CA: Jossey-Bass.

Moule P (2011) Simulation in nurse education: Past, present and future. Nurse Education Today 31(7): 645-646.

Nyback M-H (2013) A constructivist approach to teaching and learning at the Degree Programme in Nursing at Novia University of Applied Sciences. Novia University of Applied Sciences. Serie R 6/2013. Retrieved from goo.gl/x6ehta.

Nyback M-H (2016) Global Classroom - en möjlighet för heminternationalisering (Classroom - an opportunity for home internationalization). Vård i Fokus 33(3). [In Swedish]

Oliva P (2009) Developing the Curriculum (7th Edn.). Boston: Pearson, Allyn \& Bacon.

OPM (2011). Tieto- ja viestintätekniikka opetuskäytössä- välineet, vaikuttavuus ja hyödyt (ICT in teaching - tools, effectiveness and benefits). Tilannekatsaus toukokuu 2011 (Situation overview May 2011). Series: Memories for 2011: 2. [In Finnish]

Patton MQ (2001) Qualitative Research and Evaluation Methods (2nd Edn.). Thousand Oaks, CA: Sage Publications.

Phillips L (2006) Benefits of coaching as a way of developing skills and selfconfidence among nursing students. Nursing Standard 20(46): 72.

Powell K, Kalina C (2009) Cognitive and social constructivism; Developing tools for an effective classroom. Journal of Education 130(2): 241-242.

Revaitis M, Egger M (2013) FaceTime. A virtual pathway between research and practice. Nurse Educator 38(5): 186-187.

Ricketts B, Merriman C, Stayt L (2012) Simulated practice learning in a preregistration programme. British Journal of Nursing 21(7).

Rushforth H (2007) Objective structured clinical examination (OSCE): Review of literature and implications for nursing education. Nurse Education Today 27(5): 481490.

Rutherford-Hemming T (2012) Simulation Methodology in Nursing Education and Adult Learning Theory. Adult Learning 23(3): 129-137.

Seixas C, Mendes I, De Godoy S, Mazzo A, Trevizan M, Martins J (2012) Virtual learning environment: script structure of an online course. Revista brasileira de enfermagem 65(4): 660-666. 
Shin H, Sok S, Hyun KS, Kim MJ (2015) Competency and an active learning program in undergraduate nursing education. Journal of Advanced Nursing 71(3): 591-598.

Skiba D (2013) MOOCs and the future of nursing. Nursing Education 34(3): 202-204.

Splitter L (2009) Authenticity and Constructivism in Education. Studies in Philosophy and Education 28(2): 135-151.

Stevenson E, Gordon H (2014) Students as active learners and teaching partners in the clinical setting. Nurse Educator 39(2): 52-53.

Suominen R, Nurmela S (2011) Verkko-opettaja (Network-teacher). WSOYpro. [In Finnish]

Sylvest T (2010) Personal communication. Lectures held at Åbo Academic University. January - February.

Torre D, Daley B, Sebastian J, Elnicki M (2006) Overview of current learning theories for medical educators. American Journal of Medicine 119: 903-907.

Trost J (2007) Enkätboken. Studentlitteratur (Poll Book. Studentlitteratur). Lund. [In Swedish]

Wilson R, Hungerford C (2015) Mental Health Education and Virtual Learning Environments (VLEs) in Pre-registration Nursing Degrees: Follow the Leaders? Issues in Mental Health Nursing 36(5): 379-387, 